\title{
Net Neutrality Repeal and its Effect on Consumers
}

\author{
Héctor R. Lozada \\ Associate Professor of Marketing \\ Stillman School of Business \\ Seton Hall University \\ USA \\ Gary H. Kritz \\ Associate Professor of Marketing \\ Stillman School of Business \\ Seton Hall University \\ USA
}

\begin{abstract}
Net neutrality is the principle that Internet Service Providers, (ISPs), and governments should treat all data on the Internet the same, not discriminating or charging differentially by user, content, site, platform, application, type of attached equipment, or mode of communication. In early 2015, the Federal Communications Committee (FCC) adopted rules to keep the Internet net neutral denying preferential treatment for Content Providers (CPs) that are more data-rich than other CPs. By late 2017, the new chair of the FCC announced that the agency would end the net neutrality rules adopted during the Obama administration. In this paper, we explore where net neutrality rules stand, and look at both sides of the net neutrality argument. We close by discussing answers to the questions surrounding the potential effects an Internet without net neutrality could have on consumers.
\end{abstract}

Keywords: Internet, net neutrality, online content consumers, access regulations

\subsection{Introduction}

In December of 2017, the Chairman of the Federal Communications Commission (FCC), Ajit Pai, announced the Commission's decision to end the concept of "net neutrality." The commission would do so through its dismantling of regulations put in place in 2015 by the FCC itself under the Obama Administration. According to Kang (2017), these regulations were established to ensure stronger government oversight of Internet Service Providers (ISPs) and their business practices.

The demise of net neutrality caused an initial stir from the general public, congressional leaders, and state governments. Multiple lawsuits and a congressional petition were filed, or are anticipated to be filed, to block or reverse the decision to end net neutrality regulations. Assuming that the repeal of net neutrality survives all the court challenges, and the challenges from congressional lawmakers, what would the economic impact of a nonneutral internet look like for consumers? Will consumers experience slower internet service on certain websites, because companies cannot afford to pay a premium price to have faster Internet speeds? Alternatively, would it result in more network options and services for consumers, as Mr. Pai and the ISP's have claimed?

This article provides background context of net neutrality laws and the conditions on which they were rolled back. We then explore both sides of the net neutrality argument. We close by providing a path to answer the question regarding the effects an Internet without net neutrality could have on consumers.

\subsection{Background and Timeline}

In 2005, the United States Federal Communications Commission established the concept of an "open internet" with four major principles that would "encourage broadband deployment, and preserve and promote the open and interconnected nature of the public Internet." These principles were as follows (FCC 2005):

- Consumers are entitled to access the lawful Internet content of their choice. 
- Consumers are entitled to run applications and use services of their choice, subject to the needs of law enforcement.

- Consumers are entitled to connect their choice of legal devices that do not harm the network.

- Consumers are entitled to competition among network providers, application and service providers, and content providers.

These tenets for net neutrality existed as general guidelines when the FCC wrote them into law with the passing of the Open Internet Order in 2010. At that time, FCC Commissioner Julius Genachowski added to these general principles the idea that ISPs may not discriminate against content in any way (Anderson 2009). The 2010 Order was met with plenty of opposition from ISPs leading to a challenge from Verizon Wireless in the United States Court of Appeals in 2014. Verizon won that case, resulting in the Court striking down the no blocking and no unreasonable discrimination aspects of the 2010 Order. According to the Court, the FCC had not distinguished broadband service providers as telecommunication services, and therefore, these companies were exempt from being treated as common carriers subject to FCC jurisdiction (Crews 2014). In summary, while both Verizon and AT\&T are telecommunication service providers, they also provide broadband services, and this earned them the exemption in the court ruling.

In response to the Court's decision, in February 2015 the FCC adopted new regulations reclassifying all ISPs as common carriers subject to regulations ensuring that all consumers were provided fair access to their services. The ISPs were banned from having paid prioritization deals, though they could set aside fast lanes for some exceptions (Yu and Snider 2015). Predictably, the ISPs did not care for the FCC rewriting their rules after they had just earned a major victory in Federal Court. The ISPs response was to increase their influence in Washington in terms of lobbying and campaign donations.

During the 2016 election cycle, Comcast donated a total of $\$ 3.9$ million to 360 house members and 52 senators. Comcast was also the 12th biggest spender on federal lobbying with 118 lobbyists on the payroll totaling $\$ 14,330,000$ spent. In addition, AT\&T was the ninth biggest spender on federal lobbying $(\$ 16,370,000)$, spending a half million dollars more than lobbying powerhouse the Business Roundtable (West 2017). The ISPs lobbying efforts, along with Republican victories in Congress and the White House, led to the December 2017 announcement of net neutrality rollbacks by Mr. Pai, one of the commissioners who voted against the 2015 FCC regulations, and who had been appointed Chairman of a now three-to-two Republican controlled FCC by President Trump. The rollbacks were approved by the FCC in February 2018.

In response to the FCC's rollback, state governments have taken up the fight to keep net neutrality alive in the U.S. In April 2018, the state of Oregon passed and signed into law a measure that requires state agencies to do business only with ISPs that do not block, slow traffic, or accept payment to prioritize some data. California has proposed a similar bill to the one that was passed by its neighbor to the north, and several other states are considering laws preventing Internet service providers from blocking and throttling content on consumers' broadband connections.

It is extremely likely however, that these laws will continue to be challenged in court by ISPs, who will argue that the new federal rules prevent states from passing their own laws regarding net neutrality. To complicate matters, attorney generals in 23 states and the District of Columbia filed suits against the FCC in May 2018 seeking to prevent the implementation of the rollbacks, calling it arbitrary, capricious, and an abuse of discretion (Snider 2018).In late February 2018, Congressional Democrats introduced a resolution aimed at undoing the FCC's repeal of the net neutrality rules (Hendel and Gold 2018). Despite all the turmoil, six months after it was approved, the FCC's repeal of net neutrality rules took effect on June 11, 2018 (Collins 2018).

According to Collins (2018), several consumer advocates worry that broadband providers may begin selling the Internet in bundles, not unlike cable television packages. Another major concern is whether pay-to-play dealsallowing the ISPs to impose unregulated rate charges for Internet "fast lanes" and greater data usage- would be normalized and, as a result, consumers' Internet habits would suffer. Since the rules prohibiting paid prioritization no longer exist, large Internet and media companies, as well as affluent households, could occupy the fast lanes while everyone else could be left in the slow lane. Collins (2018) also points out that some small-business owners are worried that industry giants could pay to get an edge and leave them on an unfair playing field. 


\subsection{Is A Non-Neutral Internet a Bad Thing?}

Upon the announcement of the FCC rollback of the 2015 Net Neutrality regulations, Commissioner Michael O'Rielly, who voted for passing the net neutrality repeal, stated that the Internet has functioned without net neutrality rules far longer than with them. This decision will not break the Internet (Petri 2017). O'Rielly sided with the argument made by ISPs that net neutrality restrictions needed to be removed because they were strangling the ISP's ability to grow and innovate, as the Internet did for years prior to the 2015 restrictions (Petri 2017).

Steimle (2014) asserts that several of the industries with major problems (for example, health care, education, housing, and banking) have something in common: they are all highly regulated by the Federal government. In his view, the telecom industry provides a stark contrast: since this industry was deregulated, innovation has led to growth.

Proponents of Net Neutrality say the telecoms have too much power. I agree. Everyone seems to agree that monopolies are bad and competition is good, and just like you, I would like to see more competition. But if monopolies are bad, why should we trust the U.S. government, the largest, most powerful monopoly in the world?...(sic) If the telecoms are forced to compete in a truly free market, Comcast and Time Warner won't exist 10 years from now. They'll be replaced by options that give us better service at a lower price (Steimle 2014).

Steimle's argument is that net neutrality deregulation will allow the emergence of other ISPs that will compete with the big telecom/ISP companies, and this will drive down the price of service for consumers. McMillan (2014) argues further that a neutral Internet has never really existed to begin with.

Today, privileged companies_-including Google, Facebook, and Netflix - already benefit from what are essentially internet fast lanes, and this has been the case for years. Such web giants - and others - now have direct connections to big ISPs like Comcast and Verizon, and they run dedicated computer servers deep inside these ISPs... We shouldn't waste so much breath on the idea of keeping the network completely neutral. It isn't neutral now (McMillan 2014).

McMillan continues by diving straight into the first argument brought up by Steimle, stating that rather than regulation, what the public needs are ways to increase competition among ISPs because that is what will prevent the big companies from gaining so much power that they can completely control the market for internet bandwidth (McMillan 2014).

\subsection{Is Net Neutrality Needed?}

FCC Commissioner Jessica Rosenworcel argued when she voted against the rollback that she was doing so because the rollback would allow ISPs to block websites, throttle services and censor online content, ensconcing the right to discriminate. She asserted that this would rather make our broadband markets less competitive, and consumers will have no recourse (Petri 2017). Several Internet providers have pledged in the months leading up to the net neutrality repeal vote that they would not block or throttle sites, but should they be given the benefit of the doubt on this matter? Goldman (2011) reports that Verizon, AT\&T, and T-Mobile all blocked Google's mobile payment application "Google Wallet" because it competed with the mobile payment application that they had developed, which at the time was ironically called Isis, but was rebranded in 2014 as Softcard to distance itself from the militant terrorist group (Lunden 2014).

Another example of blocking and paid prioritization occurred in 2014 when Netflix reluctantly agreed to pay Comcast an exorbitant fee for Comcast to increase the speed of Netflix streams (Goldman 2014). Comcast claims it did not intentionally slow down Netflix video streams and that the slow service was caused by the Netflix's high volume of subscribers, but soon after a deal was reached that allowed Netflix to connect its servers to Comcast's network near key distribution points Netflix's streaming speeds soared. Netflix would then enter into similar deals with AT\&T, Verizon, and Time Warner Cable (Goldman 2014). This leads back to the point that big Telecom companies might not be worthy of consumers' trust, while also showing that paid prioritization may be more common in the near future of a free market Internet. 
What would a free market and open Internet actually look like for consumers? It would probably look similar to how the country of Portugal operates its Internet services. Portugal has a system set up where mobile providers offer packages that count data differently based on the apps you want to use (Feldman 2017). If a user wanted to stream videos from Netflix and Hulu without paying an exorbitant amount of data fees the user can purchase their additional \$10/month streaming package. A person wanting to access social media sites like Facebook or Instagram would add on the social-network package fee (Feldman 2017). Essentially, the Internet could become the new satellite television, where instead of paying for access to specific channel packages, consumers would have to pay for access to certain social media or video streaming websites.

\subsection{Conclusion}

FCC Chairman Ajit Pai along with Internet service providers have argued that these rollbacks are a good thing for the economy and consumers because it loosens regulations. "It's basic economics," Mr. Pai said in a speech at the Newseum in April. "The more heavily you regulate something, the less of it you're likely to get," (Collins 2017, 2018). Do the FCC and the ISPs really believe the public feels that service providers want these regulations rolled back because it will increase the choices for the consumers and therefore lead to more competition for the service providers? Alternatively, is it more likely that ISPs expect to gain much more in terms of charging fees, blocking sites, and paid prioritization?

Commissioner Pai has also long been a proponent of the idea that before the regulations went into effect in 2015, service providers had not engaged in any of the practices the rules prohibit.

Did these fast lanes and slow lanes exist? No. It's almost as if the special interests pushing Title II weren't trying to solve a real problem but instead were looking for an excuse to achieve their longstanding goal of forcing the internet under the federal government's control (Collins 2017).

As we discussed earlier, this was not necessarily the case as evidenced by Netflix paying for access to Comcast's network. However, it would be the case if Netflix increases its fees to consumers to pay for it. We must also point out that there is evidence that paid prioritization was prevalent for big tech companies prior to 2015 (see McMillan 2014).

The future of net neutrality did not align itself as one of the hottest topics for politicians leading into the 2018 midterm elections. Speaking about the issue after the Midterm elections, Finley (2018)asserts that despite multiple polls suggesting broad support for net neutrality from both Republican and Democratic voters, it was not a major factor. Consequently, we are not sure how the new Congress will deal with net neutrality, if at all, or if it would be a relevant issue in the 2020 election cycle. Finley (2018) reports that the broadband industry is currently paying lip service to some form of net neutrality legislation as a response to the lawsuits seeking to reinstate the Obama-era rules. However, the new Democratic majority in the House of Representatives will not be in a position to overturn the new FCC rule come January 2019.

Note the following specific recommendations for streaming video provided by Netflix (2018): 3 Mbps should for standard definition (SD) video, $5 \mathrm{Mbps}$ for high definition (HD) video and $25 \mathrm{Mbps}$ for ultra-high definition (4K) video (Netflix 2018). We can safely assume that Hulu and YouTube have similar requirements. Presently, several wireless operators are already bundling some of these data-rich services for their customers. A visit to the T-Mobile website on November 15, 2018 shows an offer for Netflix standard plus unlimited streaming of entertainment. This plan includes two simultaneous streams in HD, but there is an explicit indication that standard speed is approximately $128 \mathrm{kbps}$. A second example is AT\&T's Unlimited Choice\& More subscription, which costs $\$ 45$ a month for a single line (after a $\$ 10$ deduction for direct payment), offers over 30 channels live $\&$ ondemand TV and HBO (AT\&T 2018). In the fine print, however, AT\&T states that video may be limited to standard definition, that the 15 GB Mobile Hotspot per line that is included in the plan may limit its speed to a maximum of 128Kbps (AT\&T Unlimited Data Plans 2018).

Big telecom companies appear to be promising not to slow down or block websites, but at the same time, they are explicitly stating that under certain circumstances they will lower the speed of the video definition. Are consumers noticing? Whether consumers would be content by being in the "slow lanes" for the services that they currently enjoy remains to be seen. We realize that consumers would have to compare the speed/length of time it takes to transfer data on these services and websites to know if they would prefer to pay for "faster lanes" under the conditions mentioned before. 
However, if ISPs start to charge premiums for faster speeds for the services and websites that they use, will they be complacent? Our preliminary data tell us that most of those willing to pay a premium for these services and websites would not be willing to pay more than $\$ 30$ per month depending on the services offered in the bundle. In the near future, our intention is not only to study if the new Congress returns to the Obama-era rules, but also what ISPs may be preparing to do in case there is a return to the 2015 rules.

\subsection{References}

Anderson, Nate (2009).“FCC Chairman Wants Network Neutrality, Wired and Wireless.” arsTechnica.com. September 21.

AT\&T.com (2018) https://arstechnica.com/tech-policy/2009/09/fcc-chairman-wants-network-neutrality-wired-and-wireless/.

https://www.att.com/plans/unlimited-data-plans.html?WT.srch=1\&kid=aud-488124601089:kwd-

$366571850605 \& \mathrm{cid}=1523412946 \&$ source $=$ ECPS0000000PSM00P \& gclid $=$ CjwKCAiA8 $\mathrm{rnfBRB} 3 \mathrm{Ei}$

wAhrhBGlw3ok4MWTod9nesr4V3oLsjxyrqSuyLELYvt5vkNjOugI4K1_bS8BoCN0cQAvD_BwE\&gcld

=CjwKCAiA8rnfBRB3EiwAhrhBGlw3ok4MWTod9nesr4V3oLsjxyrqSuyLELYvt5vkNjOugI4K1_bS8BoCN0cQAvD_BwE.

AT\&T Unlimited Data Plans (2018).https://m.att.com/shopmobile/wireless/plans/ mobileshare.html.

Breland, A. (2018). Senate Dems to Force Vote on Net Neutrality.TheHill.com. April30. http://thehill.com/po licy/technology/3 85539-dems-plan-net-neutrality-vote-next-month.

Collins, K.(2018). Net Neutrality Has Officially Been Repealed. Here's How That Could Affect You.NYTimes.com. June 11.https://www.nytimes.com/2018/06/11/ technology/net-neutrality-repeal.html.

Collins, K.(2017). Why Net Neutrality was Repealed and How It Affects You.NYTimes.com. December 14. https://www.nytimes.com/2017/12/14/technology/net-neutrality-rules.html.

Crews Jr, C. W.(2014). Court Rules against Net Neutrality in Verizon V. FCC.Forbes.com. January 14. https://www.forbes.com/sites/waynecrews/2014/01/14/court-rules-against-net-neutrality-in-verizon-v-fcc/ \#17aaf79f2ed8.

Federal Communications Commission (FCC) (2005). Policy Statement. Federal Communications Commission.September23. https://apps.fcc.gov/edocs_public/attachmatch/FCC-05-151A1.pdf.

Feldman, B. (2017). Without Net Neutrality, What Happens to My Netflix? NYMag.com. November 21. http://nymag.com/selectall/2017/11/what-happens-to-netflix-when-net-neutrality-is-gone.html.

Finley, K. (2018). The Midterm Election Didn't Salvage Net Neutrality.Wired. November 7. https://www. wired.com/story/midterm-election-didnt-salvage-net-neutrality/.

Goldman, D.(2011). Verizon Blocks Google Wallet. CNN.com/Money. December 6, http://money.c nn.com/2 011/12/06/technology/verizon_blocks_google_wallet/ index.htm.

Goldman, D. (2014). Slow Comcast Speeds Were Costing Netflix Customers.CNN Tech. Web. 29 August. http://money.cnn.com/2014/08/29/technology/netflix-comcast/ index.html.

Hendel, J. \&Gold, A.(2018). Democrats Introduce Resolution to Reverse FCC Net Neutrality Repeal. Politico.com. February 27. https://www.politico.com/story/2018/02/27/democrats-fcc-reverse-net-neutrali ty - 426641.

Kang, C. (2017). F.C.C. Repeals Net Neutrality.The New York Times. Web. December 14. https://www. Nytimes .com/2017/12/14/technology/net-neutrality-repeal-vote.html.

Lunden, I. (2014). Isis Mobile Wallet Rebrands as Softcard to Distance from Militant Terror Group. Techcrunch. September 3.https://techcrunch.com/2014/09/03/isis-mobile-wallet-rebrands-to-softcard-to-distance-from-miltant-terror-group/.

McMillan, R (2014). What Everyone Gets Wrong in the Debate Over Net Neutrality.” Wired Business. Web. 23 June .https://www.wired.com/2014/06/net-neutrality-missing/

Netflix (2018). Internet Connection Speed Recommendations. Netflix.com, https://help. netflix.com/en/node/306

OpenSecrets.org. Net Neutrality.https://www.opensecrets.org/news/issues/net_neutrality/

Petri, A. (2017). Net Neutrality is Gone. Feel the Freedom Coursing Through Your Veins. Washington Post. Web. 14 December. https://www.washingtonpost.com/blogs/compost/wp/2017/12/14/net-neutrality-is-gone-feel-the-freedom-coursing-through-yourveins/?noredirect $=$ on\&utm_term $=.563 \mathrm{~b} 5 \mathrm{a} 9 \mathrm{da} 685$.

Snider, M. (2018). Net-Neutrality is Over. Now California, Oregon Are Stepping In. USA Today.com. April 20. https://www.usatoday.com/story/tech/news/2018/04/20/net-neutrality-repeal-prompts-calif-other-states-pursue-their-ownlaws $/ 529337002 /$.

Steimle, J. (2014). Am I the Only Techie Against Net Neutrality? Forbes.com.May 14. available at https://www.forbes.com/sites/joshsteimle/2014/05/14/am-i-the-only-techie-against-net-neutrality/\#6fcce96f70d5.

T-Mobile.com (2018). https://www.t-mobile.com/cell-phone-plans?ds_rl=1082060\&ds_rl=1254232\&ds_rl= 1260234\&cmpid=ADV_PB_ONETI440_43700017346358183\&mx_ch=ADV_PB\&_vsrefdom=431-6477513\&mchxkw=c:738972695,k:t\%20mobile\%20offers,m:e,p:1t1,d:c,ai:42587499790,ad: ,s:g\&gclid=CjwKCAiA8rnfBRB3EiwAhrhBGvdanYYiCEglWU_WJEgvSMIAT-FCG1FkpHCiAcrn4VP _18zxU00rIBoC7YUQA vD_BwE\&gclsrc=aw.ds.

West, G. (2017). Money flows into net neutrality debate ahead of FCC vote.OpenSecrets.org. December 14. https://www.opensecrets.org/news/2017/12/money-flows-into-net-neutrality-debate-ahead-of-fcc-vote/.

Yu, Roger\& Snider, M. (2015). FCC Approves New Net Neutrality Rules.USA Today. February 26. https://www.usatoday.com/story/money/2015/02/26/fcc-approves- net-neutrality-rules/24053057/.

The authors thank the Institute of International Business in the Stillman School of Business at Seton Hall University, South Orange, New Jersey, for their generous support of this research. 